TEACHING AND LEARNING ETHICS DEBATE

\title{
The white coat ceremony: a contemporary medical ritual
}

\author{
S J Huber
}

J Med Ethics 2003;29:364-366

$\mathrm{T}$ he white coat ceremony is a common practice at many American and European medical schools. Current justification for the ceremony is mainly based on the good will felt by participants and an assumed connection between the ceremony and encouraging humanistic values in medicine. Recent critiques of the ceremony faults its use of oaths, premature alignment of students and faculty, and the selective appropriation of meaning to the white coat itself. This paper responds to recent critiques by addressing their misconceptions and arguing that the white coat ceremony is a contemporary medical ritual with a key role for students and faculty in developing a professional identity.

Since its inception in 1993, the white coat ceremony (WCC) has become a national and international phenomenon. It is now practised at the beginning of the year at more than 100 American medical schools and is supported by foundation grants dedicated to endorsing and encouraging professional development and humanism in medicine. ${ }^{1}$ While some literature addresses the symbolism and history of the white coat itself, few sources consider the meaning of the ceremony. ${ }^{2-4}$ A common appeal is to the emotion and good will felt at the event. ${ }^{15}$ Although feelings are important, a deeper justification is called for.

Criticism of the WCC is more explicit, charging that the ceremony: (1) uses the Hippocratic Oath inappropriately or, at best, prematurely; (2) fosters improper student faculty relationships, and; (3) interprets the meaning of the white coat selectively.$^{67}$ Critics suggest either that students not be asked to swear an oath together because it might conflict with personally held beliefs, or that students not be allowed to take the oath until they have demonstrated competence as physicians. ${ }^{6}$ Some also say that the WCC aligns students with faculty and against patients. ${ }^{6}$ The third category of criticism asserts that the historico-anthropological meaning of the white coat itself includes more than virtue and humanism and, in fact, represents an imbalance of power, separatism, entitlement, and paternalism in medicine. ${ }^{37}$ To address only the positive connotations of the white coat in a ceremony is deemed disingenuous.

Though critics have suggested that the WCC is misused, improper, an affront to professionalism, or even unethical, these objections have serious flaws of their own. ${ }^{67}$ I will examine three criticisms and, in response, offer an interpretation of the WCC as a contemporary medical ritual that holds a beneficial place in the professional development of a medical student.

\section{THE WHITE COAT CEREMONY}

The Gold Foundation describes the WCC as an experience by which "participating schools alert beginning students to the need to balance excellence in science with compassionate patient care". ${ }^{8}$ It "helps to identify the characteristics of a complete doctor". ${ }^{8}$ The WCC began in 1993 at Columbia University's College of Physicians and Surgeons, and has since spread across the United States and the world. ${ }^{1}$ Because of the short institutional memory of medical schools and its association with the Hippocratic Oath, medical students now perceive the WCC as a longstanding tradition. A typical WCC includes the presence of family and friends, a welcome from the school administration, an inspirational message from a role model, receipt of the white coat from a physician, the swearing of an oath, and a reception with a "party atmosphere". ${ }^{8}$ Good will and positive thoughts are meant to welcome and initiate students as novices in the medical profession.

\section{STUDENTS SWEARING OATHS}

A central feature of the WCC is the recitation of a "Hippocratic or similar" oath. ${ }^{8}$ Concerning the use of oaths, philosopher and bioethicist Robert Veatch asserts that the oath is thrust upon students before they are able to decide whether they can agree with it or live up to it. ${ }^{6}$ There is no recourse for a student who does not agree with the oath, he charges, and some oaths are insensitive to student beliefs. Veatch suggests the use of a (undefined) student honour code instead. Because of the diversity of ethical traditions, "an oath to practise medicine according to one particular, idiosyncratic moral code ... is not defensible". ${ }^{6}$

In my judgment, Veatch's argument is unsound for two reasons. First, he mistakes a medical oath for a complete moral code. An oath is a statement of intent, not a complete ethical stance, nor is the whole of medical ethics merely a footnote to the Hippocratic Oath. ${ }^{9}$ When a student takes an oath, he or she is promising to behave honourably as a medical student, not as a physician. In the context of a WCC, the pledge is to learn within the parameters of these values. At graduation, one may swear to embody those values as a physician, if one desires to live that way. The examination of the professional (and shared) values of medicine (both the written codes and the professional values demonstrated by educators and practitioners) is part of the students' process of professional development. The beginning of this process is marked by the WCC. ${ }^{10}$ Swearing to an honour code, as Veatch would have new students do, is not enough. There is more to being a medical student than being an honest academic. Promising to cooperate and not cheat doesn't cover the responsibilities a student has as a clinician apprentice. Similarly, student generated codes are insufficient because they ask the students to decide what is important about the practice of medicine before they have ever experienced it and without the counsel of their mentors. Admittedly, there is difficulty in establishing who should be able to select or modify an oath, and disagreement over its wording and content. ${ }^{611}{ }^{12}$ These problems are reduced if an oath is seen as initiatory and incomplete, and if the oath and WCC are part of a larger programme of professional development. ${ }^{3}{ }^{10}$

\section{PERSONAL ETHICS}

The second weakness in Veatch's analysis is in assuming that a professional identity must derive exclusively from a personal morality. The implication is that students should reject any culturally based "medical ethic" that is not their own or of their choosing. He claims that the WCC asks students to abandon their own "religious, cultural, ethnic, 
and national identities", and to take on the stark, empty identity of contemporary medicine. He suggests that, instead, students strengthen their personal cultural identities and then "each subscribe to the medical ethic that is appropriate for that tradition". ${ }^{6}$ This intense individualism suggests that the title of physician is ethically empty and one of convenience that can be used to legitimate whatever personal ethic or tradition students bring with them to medical school. It says that you do not have to honour any distinctive obligations of physicians, you just have to be consistent with your personal ethic. While medical decision making is an individual process, it should not be purely personal. Rather, professional obligations flow from a collective professional identity. Of course, individual actions and values shape and reinvent the collective identity, but they are not separate from it. $^{1314}$ Medicine has an evolving characteristic pattern of balancing its values within a reflective equilibrium. ${ }^{15}{ }^{16}$ The pattern is a collective one, and reflection is both individual and across the profession.

This is not to deny the importance of personal morality, religion, and culture in society. Cultural and religious moral traditions are important. They are how many of us make decisions for ourselves. An understanding of that process is indispensable for physicians because it is often how patients will make decisions for themselves. It is not necessarily how professional decisions should be made in medicine. There are certain values and responsibilities in medicine that are, in principle, not negotiable because they represent medicine's characteristic pattern of organising values. If one's personal values conflict significantly with those of the "good doctor," then it is not necessarily reasonable or defensible to ignore the professional values. Instead, a careful reassessment of one's career plans may be in order-for example, a medical duty to conduct a comprehensive physical examination exists notwithstanding personal, religious, and cultural prescriptions surrounding modesty, bodily privacy, and interaction with those of the opposite sex. The professional development that begins with the WCC should include reflection on these possible conflicts. A pledge to explore them ethically and honestly as a student begins that process.

\section{KEEPING STUDENTS AND FACULTY SEPARATE}

Veatch considers the bonding process that occurs between students and their faculty at the WCC to be detrimental to patients because it separates students from the "lay" population, making them more like priests and disconnecting them from the needs of lay groups. ${ }^{6}$ I disagree. The bonding between the two groups at the WCC is a sign of the faculty's confidence in the students more than a removal of the students' character and culture. It is a statement that medical school is difficult, made by those who contribute to its rigour, and followed by a supportive gesture that says: "I believe you can do it". Bonding and support should not be mistaken for isolation and detachment. Patient care and student caring is enhanced through the long standing tradition of physician student mentoring.

\section{WHITE COAT CEREMONY AS CONTEMPORARY RITUAL}

As noted by medical educator Delese Wear, the WCC should not be the end of formal professional development. ${ }^{3}$ In fact, because of the strong influence of the hidden or informal curriculum on students, the WCC is meaningless as a curricular event if the institution does not embody and demonstrate the values it professes at the public ceremony. ${ }^{317}{ }^{18}$ Wear suggests getting rid of the WCC altogether because it imparts values such as social and economic entitlement rather than only compassion and humility. Instead, I would argue that it should remain as an important ritual in contemporary medical education precisely because of the varied meanings found in the white coat and the medical profession. The WCC is a ritual that appropriates meaning to the white coat and helps students cross the temporal and physical boundary from wherever they were before (college, a different career) into the world of thinking and learning about the practice of medicine. It is a ritual of initiation, not one of graduation or completion. Like any good ritual, it has symbols, its own language, and an appeal to an idea larger than the individual. It begins the development of a particular type of identity: that of the medical professional. It should be a little exciting and a little terrifying because of the perceived gravity of the situation. The white coat emerges from the ritual as a symbol of professionalism and humanism, and remains a tacit reminder throughout medical school. It is often commented that one takes on a new identity as one dons the white coat. When viewed in this light, the WCC is a useful and important step in the professional development of a contemporary medical student. Furthermore, as an annual ceremony, the WCC can serve to remind faculty of the importance of teaching and demonstrating humanistic and ethical practice.

As noted above, an essential feature of ritual is the creation and appropriation of meaning. Philip Russell, a final year medical student at the time he wrote his critique of the white coat ceremony, is disturbed by this aspect of the WCC. ${ }^{7}$ Russell argues that the WCC picks and chooses the meanings it appropriates to the white coat and therefore to medical students. This is precisely the point of a ritual. The creation of ritual meaning allows us to reclaim a symbol from its muddled or contradictory historical connotations. It is true that the ceremony is disingenuous if it proposes values that are not demonstrated in medicine, but this need not be the case with the WCC. The white coat has been taken to stand for virtue and excellence in medicine, but has also stood for paternalism, abuses of power, and austere separation between physician and patient. ${ }^{3}$ It is this multiplicity of meaning that the WCC ritual can seek to sort out.

\section{TRUST AND POWER}

Much like Veatch, Russell's analysis mistakes a ritual of initiation for one of completion, which leads him to object to what he sees as an inappropriate conferral of unearned trust and status to medical students through the ceremony. ${ }^{7}$ The WCC is more like a bar mitzvah or confirmation than a medical school graduation. It says: "you have studied enough to be admitted as a novice, now go about becoming a full fledged member". When the WCC is viewed as an initiation and first step, Russell's objection to the appropriation of status trust and merit trust becomes moot. The initiate is granted a certain amount of authority and status trust, but not much of either. Rather than creating a sense of entitlement, as Russell claims, the WCC makes explicit the role of power and trust in the therapeutic (and educational) relationship. Merit trust is not conferred until graduation, the bookend ritual to the WCC.

Finally, and most disturbingly, Russell seeks to link the WCC to a perceived decline in the power (by which he means autonomy and financial status) of the medical profession. He grounds this attack in a misunderstanding of the definition and meaning of professionalism. Citing medical sociologist Elliot Freidson, Russell describes the "most basic tenet of any profession: [as] restricted access to a protected body of information". ${ }^{7}$ Russell then calls the decline of such restricted access erosion of professional power. A closer reading of Freidson reveals that Freidson rejects Goode's notion of access to information as a formal criterion for a profession. Instead, he opts for occupational autonomy as the standard for a profession. ${ }^{19}$ Such autonomy is granted through a 
relationship with society at large. Any medical professional who thinks that patients are better off knowing less about their health, or that medical power is generated solely through the withholding or restricting of information is sorely mistaken. From public health education campaigns to relationship centred care, medicine has moved to increase patient autonomy and endorse the understanding of one's own health and body. Medical power comes from relationships and the arts and sciences of healing, not from the sequestering of esoteric knowledge.

Anthropologically, the white coat, like medicine itself (and as a symbol of medicine) has had different meanings in recent history. ${ }^{3}{ }^{7}$ On this point, Russell is correct. While he objects to the ritual because it explicitly creates meaning, viewing this as somehow corrupt, I have suggested that the appropriation of meaning is the explicit purpose of a WCC as ritual. Raanan Gillon, a physician, ethicist, and educator at the University of London, describes his experience as an observer at a WCC, and helps us understand why the WCC is important. ${ }^{5}$ He notes the similarity between student and physician commitments, and the utility of connecting students to the idea of humanistic competence and not just scientific or technical ability at the beginning of their careers. ${ }^{5}$ When viewed in light of the Gold Foundation's goals, the WCC is a step in professional development that associates some of the best qualities we would like to see in physicians with the incoming students themselves. It can help to align medical students and medical faculty around worthy professional values.

\section{CONCLUSION}

The WCC is a well crafted ritual that appropriates meaning to a symbol and helps initiates a move through an exciting yet daunting time in their lives. It allows the faculty to set up a framework for understanding the education that is to come. Taking an oath of initiation and being supported by the community of physicians places the student at the beginning of the development of a professional identity. The content and expression of this identity will be more greatly influenced by the student's experiences in the hidden curriculum and demonstrated values of the training institution. Nevertheless, the WCC is a useful first step in the professional development of a caring, humanistic physician. As a curricular event and a bookend ritual with graduation, it should be continued and encouraged as a practice in medical education.

\section{DISCLAIMER}

The views and opinions contained in this article are those of the author and should in no way be construed as representing official policies or positions of the American Medical Association.

\section{ACKNOWLEDGEMENTS}

I wish to thank Faith Lagay, PhD, and Ken Kipnis, PhD, for helpful discussions and critical review of the manuscript.

Correspondence to: S J Huber, Institute for Ethics, American Medical Association, 515 N State Street, Chicago, IL 60610, USA; S J Huber; shuber@urgrad.rochester.edu

Accepted for publication 12 November 2002

\section{REFERENCES}

1 Medical students: transitional experiences. Arnold P Gold Foundation website: www.humanism-in-medicine.org (accessed 11 Mar 2002).

2 Rothstein RM. The white coat ceremony. Mt Sinai J Med 2001;68:224-5.

3 Wear D. On white coats and professional development: the formal and hidden curricula. Ann Intern Med 1998;129:734-7.

4 Blumhagen DW. The doctor's white coat: the image of the physician in modern America. Ann Intern Med 1979:91:111-16.

5 Gillon R. White coat ceremonies for new medical students. J Med Ethics 2000;26:83-4

6 Veatch RM. White coat ceremonies: a second opinion. J Med Ethics 2002;28:5-6.

7 Russell P. The white coat ceremony: turning trust into entitlement. Teach Learn Med 2002; 14:56-9.

8 Components of the white coat ceremony. Arnold P Gold Foundation website: www.humanism-in-medicine.org (accessed 11 Mar 2002).

9 Baker R. The history of medical ethics. In: Bynum WF, Porter R, eds. Companion encyclopaedia of the history of medicine, [vol 2]. London: Routledge, 1997:852-87

10 Rhodes R. Enriching the white coat ceremony with a module on professional responsibilities. Acad Med 2001;76:504-5.

11 Sritharan K, Russell G, Fritz Z, et al. Medical oaths and declarations. BM 2001;323:1440-1.

12 Stevenson WT. Declarations for new doctors are unnecessary. BMJ 2002;324:851.

13 Durkheim E. The elementary forms of religious life. Paris: Alcan, 1912; New York: Simon and Schuster, 1995:xliii, 223, 447.

14 Huber S. Keeping the trust. Professing Medicine 2002;1:86-8.

15 Hundert EM. A model for ethical problem solving in medicine, with practical applications. Am J Psychiatry 1987; 144:839-46.

16 Rawls J. A theory of justice. Cambridge: Harvard University Press, 1971:48-9.

17 Hundert EM, Hafferty F, Christakis D. Characteristics of the informal curriculum and trainees' ethical choices. Acad Med 1996;71:624-42.

18 Swick HM, Szenas P, Danoff D, et al. Teaching professionalism in undergraduate medical education. JAMA 1999;282:830-2.

19 Freidson E. Profession of medicine: a study of the sociology of applied knowledge, [2nd ed]. Chicago: University of Chicago Press, 1988:71-84. 